\title{
EXPERIÊNCIAS DE TRABALHO DE PROFESSORES EXPERIENTES DA EDUCAÇÃO BÁSICA: QUALIDADE DE VIDA E ESGOTAMENTO PROFISSIONAL
}

DOI: $10.22289 / 2446-922 X . V 2 N 2 A 5$

\author{
Lidiane Bruna da Silva \\ Alex Garcia Cunha ${ }^{1}$
}

\section{RESUMO}

Trata-se de uma pesquisa com o objetivo de mapear experiências profissionais de professores experientes da educação básica pública visando compreender sua qualidade de vida no trabalho, observando a eventual inter-relação dessas experiências com indícios de esgotamento profissional. Os dados foram coletados por meio de uma ficha de informação sociodemográfica e uma entrevista semiestruturada aplicadas a cinco professores do ensino fundamental e médio de uma escola pública. Os dados foram analisados qualitativamente por meio de categorias criadas a partir da literatura da área do estudo e dos padrões que emergiram da leitura dos dados. Os resultados mostram que os professores enfrentam uma rotina pesada de trabalho, o que desencadeia cansaço, alimentação em horários irregulares, trabalho após o expediente, falta de momentos de lazer e sintomas como dores de cabeça e no corpo. Isso impacta negativamente sua qualidade de vida, mas, apesar disso, relatam se sentir realizados na profissão e buscam maneiras de contornar tais adversidades. Apenas uma professora relatou adoecimento ao longo de seus anos de trabalho, precisando se afastar temporariamente. Os demais não se queixam de adoecimento. As experiências de trabalho dos participantes deste estudo indicam prejuízos em sua qualidade de vida, mas não indicaram indícios significativos de esgotamento profissional.

Palavras Chave: Experiências de trabalho, Professores, Qualidade de vida, Esgotamento profissional.

\section{ABSTRACT}

This study aimed at mapping work experiences of experienced public education teachers in order to understand their quality of life at work by considering some possible interrelationship of such experiences with burnout syndrome evidence. We collected the data through a sociodemographic information form and a semi-structured interview applied to five teachers of elementary and secondary education in a public school. We analyzed the data qualitatively by

\footnotetext{
${ }^{1}$ Endereço eletrônico de contato: alexgarciacunha@gmail.com
}

Recebido em 01/12/2016. Aprovado pelo Conselho Editorial e aceito para publicação em 16/01/2016.

Rev. Psicol Saúde e Debate. Jan., 2017:2(2):76-95. 
using categories established from the literature and patterns that emerged from the data. The results show that teachers face a heavy work routine, which triggers tiredness, eating at irregular hours, working overtime, lack of leisure time and symptoms such as headaches and body pain. Although the results showed that this negatively affected their quality of life, they reported a feeling of accomplishment towards their job and struggled to overcome adversities. Only one teacher reported illness during her career; the other ones did not complain of illness. In sum, although the work experiences of the participants affected negatively their quality of life, they did not present clear symptoms of burnout syndrome.

Key Words: Work experience, Teachers, Quality of life, Burnout.

\section{INTRODUÇÃO}

A expressão qualidade de vida foi empregada com maior repercussão pela primeira vez em 1964 pelo presidente dos Estados Unidos, Lyndon Johnson, ao declarar que "os objetivos não podem ser medidos através do balanço dos bancos; eles só podem ser medidos através da qualidade de vida que proporcionam às pessoas"(1).

A Organização Mundial de Saúde definiu, em 1994, qualidade de vida como a percepção que um indivíduo tem do seu lugar na vida, no contexto da cultura e do sistema de valores nos quais vive, em relação com os seus desejos, as suas normas e as suas inquietudes ${ }^{(2)}$. Trata-se de um conceito amplo, que pode ser influenciado de maneira complexa pela saúde física do indivíduo, pelo estado psicológico e pelo seu nível de independência, pelas suas relações sociais e suas relações com os elementos essenciais do seu meio.

Nessa direção, a qualidade de vida no trabalho é tão importante quanto a vida pessoal, pois a satisfação e o contentamento em ambos os aspectos são importantes para manter a vida equilibrada ${ }^{(3)}$. Algum desses aspectos em desarmonia pode prejudicar o outro, gerando insatisfação e problemas que interferem na vida do sujeito. Nessa perspectiva, para que a qualidade de vida exista, o indivíduo não pode ser enxergado por partes, mas sim, como um todo, como um ser biopsicossocial com seus potenciais psicológicos, biológicos e sociais.

A qualidade de vida é de considerável importância individual e coletiva em qualquer ambiente de trabalho. Sem isso, o indivíduo fica sujeito a não realizar bem suas tarefas, sua atenção fica defasada e as atividades e rotinas diárias ficam comprometidas.

Em relação à profissão de professor, esses profissionais têm, por via de regra, uma rotina de trabalho extremamente exaustiva, com carga horária excessiva, baixos salários, condições precárias de trabalho, conflitos existentes com a comunidade escolar e outras cobranças demasiadas ${ }^{(4)}$. Além disso, os professores, ao encarar situações novas, são obrigados a atribuir novos sentidos à sua atividade de trabalho, necessitando cada vez mais de disponibilidade de tempo para ensinar, realizar novos estudos, idealizar projetos 
interdisciplinares e trabalhos de campo e, ainda, planejar e executar práticas mais dinâmicas que retome a atenção dos alunos para a sala de aula(5). Todo esse contexto repercute na qualidade de vida desse profissional, gerando esgotamento profissional.

O esgotamento profissional, também conhecido por síndrome de "burnout" (queimarse, exaurir), é adquirido através do alto índice de estressores emocionais e crônicos. Dentro desse esgotamento profissional, são encontradas diversas características que favorecem o seu agravamento, destacando-se a exaustão emocional, a despersonalização e a baixa realização profissional. A exaustão emocional acontece quando o indivíduo não acredita mais em seu potencial para concluir o trabalho ou se autoavalia negativamente; há falta de energia e de recursos emocionais próprios e constante sentimento de frustração devido ao contato diário com os problemas ${ }^{(6)(7)}$.

Na despersonalização, há sentimentos e atitudes negativas, ausência de afetividade, e coisificação. Não há envolvimento pessoal nas atividades laborais, nem habilidade para a realização do trabalho, atendimento ou contato com outras pessoas. Ocorre um endurecimento afetivo e o profissional passa a tratar clientes e colegas como objeto.

Por sua vez, a baixa realização profissional é observada quando as atividades ocupacionais são prejudicadas, gerando a ineficiência, a insatisfação, o sentimento de insuficiência e, por conseguinte, a baixa autoestima, fazendo com que o profissional não perceba seu trabalho como algo valorizado e/ou reconhecido(8).

A lei no 3048/99 reconhece o esgotamento profissional como doença do trabalho, e desde maio de 1996 a Previdência Social o regulamentou como um dos agentes patogênicos causadores de doenças profissionais, no grupo das doenças consideradas de etiologia

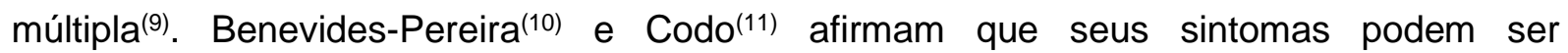
subdivididos em físicos, psíquicos, comportamentais e defensivos, os quais são elencados a seguir:

a) Sintomas físicos: fadiga constante e progressiva, distúrbios do sono, dores musculares e osteomusculares, cefaleias, enxaquecas, perturbações gastrointestinais, imunodeficiência, transtornos cardiovasculares, distúrbios respiratórios, disfunções sexuais e alterações menstruais em mulheres.

b) Sintomas psíquicos: falta de atenção, alterações de memória, lentificação do pensamento, sentimento de alienação e solidão, impaciência, sentimento de 
insuficiência, baixa autoestima, labilidade emocional ${ }^{1}$, dificuldade de autoaceitação, astenia, desânimo, disforia², depressão, desconfiança e paranoia.

c) Sintomas comportamentais: negligência ou excesso de escrúpulos, irritabilidade, incremento da agressividade, incapacidade para relaxar, dificuldade na aceitação de mudanças, perda de iniciativa, aumento do consumo de substâncias (bebidas alcoólicas, café, fumo, tranquilizantes, substâncias ilícitas, etc.), comportamentos de alto-risco e suicídio.

d) Sintomas defensivos: tendência ao isolamento, sentimento de onipotência, perda do interesse pelo trabalho e lazer, absenteísmo, ironia, cinismo.

Em relação a pesquisas realizadas acerca do esgotamento profissional, a Confederação Nacional de Trabalhadores em Educação (CNTE), em parceria com a Universidade de Brasília, realizou, em 1999, a primeira pesquisa sobre esgotamento profissional de professores no Brasil(12). A pesquisa teve 52 mil entrevistados em 1.440 escolas nos 27 estados brasileiros. Os dados coletados revelaram que $48 \%$ dos educadores apresentavam algum dos sintomas de esgotamento profissional.

A CNTE investigou novo estudo com professores em 2004(12). Este foi realizado em dez estados brasileiros e revelou que $30,4 \%$ dos professores e funcionários de escolas haviam tido ou tinham, naquele momento, problemas de saúde. Destes, 22,6\% afastaram-se temporária ou definitivamente do trabalho. De acordo com o estudo, os baixos salários faziam com os professores tivessem de lecionar em mais de um turno ou escola, sacrificando seu período de descanso e lazer. Ainda de acordo o estudo, o mau comportamento de alunos, a multiplicidade de papéis e as atividades burocráticas que precisam desempenhar contribuem para o agravo da situação, fato este também constatado por Carlotto e Palazzo(13).

Ademais, como observam Gasparini, Barreto e Assunção(14), em muitos casos as condições físicas e os materiais pedagógicos que serviriam para dar suporte ao ensino são extremamente precárias ou quase inexistentes, gerando desestímulo para o professor. Não bastasse, os alunos, a escola, a família e a sociedade que cobram mais competência do

\footnotetext{
${ }^{1}$ Labilidade emocional ou instabilidade afetiva é um estado especial em que se produz a mudança rápida e imotivada do humor ou estado de ânimo, sempre acompanhada de extraordinária intensidade afetiva. (Fonte: www.psiqweb.med.br. Acesso em 09/11/2015)

2Disforia é uma mudança repentina e transitória do estado de ânimo, tais como sentimento de tristeza, pena, angústia. É um mal-estar psíquico acompanhado por sentimentos depressivos, tristeza, melancolia e pessimismo. (Fonte: www.psiqweb.med.br. Acesso em 09/11/2015)
}

Rev. Psicol Saúde e Debate. Jan., 2017:2(2):76-95. 
profissional além daquela relacionada à sua disciplina; este deve possuir conduta exemplar, fazer com que seu trabalho seja visível e empenhar-se para conseguir manter-se saudável.

Um estudo com amostra de quase 39 mil trabalhadores em educação no Brasil identificou que $32 \%$ dos indivíduos apresentavam baixo envolvimento emocional, $25 \%$ apresentavam exaustão emocional e $11 \%$ apresentavam quadro de despersonalização(15). Para Carlotto e Câmara(8) e Benevides-Pereira ${ }^{(16)}$, esse quadro de despersonalização é observado quando o professor passa a executar suas atividades de forma mecânica, automática, podendo apresentar desumanização, evidenciando atitudes rudes, irônicas e/ ou agressivas.

Em síntese, o trabalho docente é uma atividade que promove estresse, refletindo diretamente sobre a saúde física e mental e gerando impacto no desempenho profissional do professor. Quando o professor é acometido por esse esgotamento, ele passa então a ver seu trabalho apenas como uma forma de ganhar dinheiro, um meio para sobrevivência, perdendo seu valor humanista. Os alunos e todo o universo que compõe a sua atividade profissional passam a ter um tratamento de objeto, descaracterizando sua profissão(10)(13).

As pesquisas realizadas sobre qualidade de vida e esgotamento profissional de professores utilizam-se, sobretudo, da metodologia quantitativa por meio da utilização de questionários semiestruturados(17). Todavia, pesquisas de natureza qualitativa são necessários quando se busca compreender a interioridade das dimensões do esgotamento profissional, levando-se em consideração as características do contexto e do tempo no qual os sujeitos estão imersos ${ }^{(17)}$.

Alinhado a essa necessidade de pesquisa, este estudo buscou mapear experiências profissionais de professores mais experientes (mais de dez anos de profissão) da educação básica pública, visando compreender sua qualidade de vida no trabalho, observando a interrelação dessas experiências com indícios de esgotamento profissional, caso observados. Objetivou-se identificar se os anos de exercício da profissão trariam impacto significativo no tocante ao esgotamento profissional desses profissionais.

Considerando-se o contexto de trabalho em que vivem os professores da rede pública no Brasil, partimos da hipótese de que esses professores sinalizariam qualidade de vida insatisfatória no trabalho e indícios de esgotamento profissional.

\section{PROCEDIMENTOS METODOLÓGICOS}


Trata-se de um estudo de natureza qualitativa, ou seja, que busca investigar um universo de significados, motivos, aspirações, crenças, valores e atitudes. Ou seja, relações, processos e fenômenos que não podem ser reduzidos apenas a operações variáveis ${ }^{(18)}$.

Após a aprovação por Comitê de Ética em Pesquisa - Parecer 1.686.476 -, visitamos uma escola da rede estadual de ensino localizada em um bairro de fácil acessibilidade aos pesquisadores. Tendo como critério de inclusão professores do ensino fundamental e/ou médio há mais de dez anos (professores já experientes) e excluindo professores afastados de suas atividades profissionais, selecionamos cinco professores que se dispuseram a participar voluntariamente do estudo.

Para resguardar suas identidades, nem o nome da escola nem o nome dos professores nesta pesquisa foram divulgados. Os professores receberam, a critério dos pesquisadores, pseudônimos todos iniciando com a mesma letra, por exemplo, Maria, Mercedes, Marcos etc. O nome da escola participante também foi resguardado.

Primeiramente, foi aplicado, aos professores, o Termo de Consentimento Livre e Esclarecido (TCLE). A seguir, foi preenchida uma ficha de informações sociodemográficas e, então, realizada uma entrevista semiestruturada. Essa entrevista foi gravada em áudio e integralmente transcrita logo após a sua realização.

Para a análise dos dados, primeiramente foi descrito o perfil de cada professor com base na ficha sociodemográfica. A seguir, as transcrições das entrevistas semiestruturadas foram analisadas qualitativamente, buscando-se compreender as experiências registradas.

A tarefa inicial de uma análise qualitativa é a organização, classificação e codificação dos dados ${ }^{(18)}$. Para o autor, essa categorização deve ocorrer a partir da classificação dos dados selecionados, delineando-se unidades-base de análise. Nesta pesquisa, portanto, foram privilegiados os itens que contemplam a literatura sobre a área do estudo, delineados na introdução deste estudo, e os padrões que emergiram dos dados, os quais foram utilizados com o propósito de agrupá-los de acordo com a similitude que apresentam ${ }^{(18)}$. As experiências vivenciadas pelos professores foram descritas então, interpretando-se as características contextuais desses padrões.

\section{RESULTADOS E DISCUSSÃO}

\subsection{Perfil dos participantes}

Analisando-se a ficha sociodemográfica aplicada aos professores participantes da pesquisa, descrevemos, a seguir, seu perfil: 
Maria, 47 anos, graduou-se em Letras em uma instituição de ensino superior (IES) privada em 1991. Em 2003 concluiu pós-graduação em Letras também em IES privada. Tem lecionado português há quinze anos em diversas escolas de ensino fundamental e médio.

Manoela, 55 anos, também se graduou em Letras em uma IES privada em 1994. Em 1995 concluiu a pós-graduação em Linguística em IES privada. Leciona há quinze anos no ensino fundamental e médio.

Márcia, 55 anos, graduou-se em História em 1992 e em Geografia em 2003, em IES privada. Em 1997 concluiu a pós-graduação em História da Educação Brasileira em IES privada. Leciona Geografia há dezesseis anos na escola onde este estudo foi realizado.

Mercedes, 48 anos, graduou-se em Química em IES privada em 1993. Em 1996 concluiu a pós-graduação em Química em IES privada. Em 1997, concluiu graduação em Física em IES privada. Tem lecionado Química há vinte e três anos em diversas escolas com ensino médio.

Marcos, 61 anos, graduou-se em Matemática em IES particular em 1990. Em 1991 fez pós-graduação também em Matemática na mesma IES e em 2014 concluiu o mestrado em IES pública. Tem lecionado há vinte e seis anos em diversas escolas do ensino fundamental e médio. Em 2014 ingressou como professor do ensino superior.

Para a análise das entrevistas, as seguintes categorias emergiram dos dados, as quais foram divididas entre aquelas relacionadas à qualidade de vida no trabalho e ao esgotamento profissional. Quanto à qualidade de vida, analisamos as seguintes categorias: realização de atividade física, alimentação saudável, lazer e realização profissional. Já no tocante ao esgotamento profissional, analisamos os sintomas físicos, psíquicos, comportamentais e defensivos. A seguir, trataremos de cada uma dessas categorias.

\subsection{Experiências relacionadas à qualidade de vida}

\subsubsection{Realização de atividade física}

De acordo com Lima, Levy e Luiz ${ }^{(19)}$, a atividade física é uma das formas de retardar o desenvolvimento das doenças crônicas não transmissíveis. Nesse quesito, todos os professores revelaram ter ciência da importância da prática de atividade física, embora apenas Márcia a faça diariamente, fazendo caminhadas. Maria também revela fazer caminhada três vezes na semana. Manoela, por sua vez, destaca que sua agenda de trabalho é cheia e que a prática de atividades físicas deixa a desejar. Destaca, no entanto, que quando a faz, sente-se melhor:

Rev. Psicol Saúde e Debate. Jan., 2017:2(2):76-95. 
[...] também tem aquela questão que às vezes a gente corre tanto, não faz atividade física e acaba ficando também assim, um pouco a desejar, mas quando estou fazendo atividade física, o corpo fica melhor. [...] Eu faço caminhadas [...].

(Manoela)

Já Marcos e Mercedes revelam não praticar atividade física. Segundo eles, o excesso de trabalho e a dedicação à família são empecilhos:

Não pratico nenhuma atividade física, a não ser que ficar em pé [...] (Marcos)

Não tenho tempo para fazer atividade física, não tenho devido ao trabalho e a família.

(Mercedes)

Ou seja, os relatos mostram que o volume de tarefas desempenhadas pelo professor dificulta a realização de atividades físicas, aspecto este já apontado por estudiosos(20). Diante dessa realidade vivenciada pelos professores, sugerimos que as escolas busquem promover, em parceria com educadores físicos ou instituições privadas, a realização de ginástica laboral ou alguma atividade física no próprio ambiente de trabalho, a fim de que os professores possam desfrutar dos benefícios que essa prática traz à sua saúde física e mental.

\subsubsection{Alimentação}

O volume de atividades realizadas pelos professores também dificulta terem uma alimentação de natureza saudável e em horários adequados. Manoela, Márcia e Maria descrevem sua rotina de alimentação. Elas destacam que apesar do volume de trabalho, tentam manter uma alimentação mais saudável, trazendo lanches de casa para a escola:

[...] as refeições? Boa pergunta! ((risos)) É meio complicado. Às vezes não são feitas de forma adequada não, né? Inclusive nesse ano estou na escola e tem dia que fico aqui de manhã e à tarde direto e aí [...] acaba que as refeições ficam comprometidas e não tendo aquela alimentação adequada como deveria. Então professor é muito aquela 
coisa de ficar comendo às vezes bolachinha de sal ((risos)) É uma correria o negócio! Mas na medida do possível eu consigo organizar isso de certa forma... Assim, salada, né, frutas, mas com certeza fica algo a desejar mesmo... [...] mas nada de fast-food...

(Manoela)

[...] trago de casa um lanchinho e na hora do recreio eu como esse lanche, almoço em casa...

(Márcia)

Minha alimentação é normal na medida do possível, porque tem dias que eu passo direto de uma escola para outra, então as vezes eu nem almoço, mas na maioria dos dias é até uma alimentação equilibrada. (Maria)

Para Marcos a visão de uma alimentação saudável vai além, pois ele possui diabetes, o que o faz consumir os alimentos certos, já que sem eles poderia ter algum tipo de agravamento da doença:

Minha alimentação precisa ser saudável e balanceada já que sou diabético [...]

(Marcos)

A professora Mercedes faz o consumo diário de alimentos saudáveis, pois almoça em casa e fica mais fácil balancear o que comer:

Almoço em casa, então é mais fácil não comer qualquer tipo de coisa $[\ldots]$.

Em síntese, observa-se que o volume de trabalho atribuído ao professor tem impacto direto em sua alimentação, pois geralmente o profissional não dispõe do tempo necessário para realizar suas refeições de maneira adequada.

Diante desse quadro, é preciso que a escola promova cursos de educação alimentar para seus professores, instruindo-os, por meio de oficinas e cursos, quanto a alimentos práticos e saudáveis que possam ser comprados/preparados e consumidos mesmo em uma 
rotina de trabalho em regra apertada. A escola, em seu papel de estimular uma alimentação saudável a seus alunos, não pode deixar de lado o professor, alicerce de todo o processo educacional e promotor primeiro da conscientização das crianças quanto a uma boa educação alimentar.

\subsubsection{Lazer}

O lazer é constituído de momentos agradáveis, em que se faz o que gosta e se desfruta de si mesmo. Nessa perspectiva, Marcos e Márcia revelaram desfrutar desses momentos, não relatando queixas em relação a isso:

[...] eu gosto muito de futebol, assistir é, gosto de jornal, leio muito jornal, assisto jornal e não tenho saído muito de casa não, saio fim de semana com a família, como pizza.

(Marcos)

Ah eu gosto de ir pra festa, eu gosto de ir para barzinho, eu gosto de estar com os amigos é, cinema, teatro.

[...]

[...] e vou sempre assim, passeando, procurando distrair, ter lazer né, pra gente poder descansar e voltar renovada na próxima semana. (Márcia)

Já Maria, quando Ihe é perguntado sobre como aproveitava os momentos de lazer, primeiramente demonstrou ironia por meio de uma fala em que a primeira impressão foi a de que ela desconhecia tal assunto: "Que final de semana amiga? ((risos)) Você está falando em que língua? ((risos))". Mas, após esse breve momento, revelou ter momentos de lazer em passeios nos finais de semana livres. Salienta, no entanto, que para ter finais de semana livres, precisa trabalhar a mais depois do expediente de trabalho:

[...] Bom, eu tenho alguns finais de semana do ano que eu falo assim: "hoje eu não tenho nada para fazer" e, muitas vezes, é porque eu faço a noite depois que eu chego da aula às $17 \mathrm{~h} 30$. Eu prefiro fazer nesse período da noite pra deixar o final de semana livre [...].

Rev. Psicol Saúde e Debate. Jan., 2017:2(2):76-95. 
[...] Eu vou muito para a casa do meu namorado [...], é que nós temos tipo uma pousada, só que eu vou não para a pousada, eu fico na casa dele lá só vendo filme, descansando. Aqui em Patos às vezes vou ao cinema [...], Festa do Milho eu vou todos os dias.

[...]

[...] Eu e minha filha, a gente sai pra comer alguma coisa, sai pra dar uma volta no centro, às vezes sábado à tarde, pra tomar sorvete e tal [...].

(Maria)

A professora Manoela considera bem escassos os momentos de lazer e sabe da importância que eles têm para uma vida saudável, deixando claro em suas falas que o tempo para isso é exíguo, expressando desejo de poder articulá-lo melhor. Em suas palavras:

O lazer, nossa esse deixa a desejar muito, mas é muito mesmo, esse assim é comprometidíssimo porque acabo me desorganizando devido a essa correria, aí chega final de semana e digamos assim, vou organizar um pouco minha vida, questão de trabalho em casa e ai o lazer fica realmente, ai deixa um pouquinho a desejar, dou uma descansada, mas é muito mínima [...].

[...] eu faço caminhadas e quando posso dou uma saída para o campo para dar uma espairecida [...].

(Manoela)

Do mesmo modo, Mercedes revela em suas falas que o lazer é mínimo e que com as diversas tarefas que acompanham a docência, fica muito difícil conciliar momentos de lazer, principalmente com a família, e, quando acontecem, são "cronometrados":

O lazer é basicamente muito pouco, quase que inexistente né, mas, mesmo assim a gente procura... ((risos)) assim, contornar a situação e separar um tempo pra preparar as aulas e um tempo pra dar atenção 
para os filhos então às vezes, [...] quase sempre a gente vai para fazenda mais de horário cronometrado.

(Mercedes)

Os resultados deste estudo corroboram outros estudos, que mostram que a quantidade de professores que desfrutam de fato de momentos de lazer ainda é pequena. Exemplo disso é a pesquisa realizada com 808 professores da rede municipal da Bahia ${ }^{(21)}$. Os resultados revelaram que somente $34,4 \%$ desfrutam de momentos para lazer.

\subsubsection{Realização profissional}

A realização profissional vai além do trabalho e que a motivação para uma atividade bem feita faz com que o indivíduo sinta-se melhor (22). Dessa maneira, todos os professores revelam satisfação em ser professor. Essa satisfação se manifesta especialmente pelo sentimento de recompensa e gratidão ao ver a aprendizagem e a realização de seus alunos.

[...] ser professor para mim é ser importante, é gratificante, é como se você tivesse nas mãos o caminho ou os caminhos para ensinar para quem está aprendendo com você e recebendo seus ensinamentos, suas aulas.

[...]

[...] sala de aula é o melhor lugar do mundo pra mim, o que me cansa em ser professor é o em torno, não sala de aula, o contato com o aluno me fortalece. (Marcos)

Ah eu acho assim que todo trabalho, qualquer que seja ele é digno e ele traz realização, então eu vejo muito meus alunos, por exemplo, eu já consultei com médicos que já foram meus alunos, entendeu então quando você vê assim a pessoa bem, a pessoa encaminhada/ e o contrário também de quando a gente vê ex-alunos no tráfico, preso, de certa forma isso traz certa angústia. (Maria)

[...] Ah uma palavra pra eu resumir digamos assim, deixe-me ver, é diria que gratidão mesmo, em uma palavra seria gratidão, em busca de sempre querer mais e mais, no sentido de buscar mais e mais, mas, 
gratidão mesmo, assim ((risos)) é, pelas pessoas que sempre estiveram a minha volta [...]. (Manoela)

[...] é um amor que eu tenho pelo o que eu faço e a cada dia que passa tenho certeza plena e absoluta de que eu sempre fiz e irei fazer o que eu amo que é ser professora. (Márcia)

Gratificante eu acho que seria o termo ideal, porque é muito bom quando você prepara a aula e vê que o aluno conseguiu né... (Mercedes)

Ou seja, os professores deste estudo concebem sua profissão como algo positivo, sublime, essencial para a transformação de seus alunos, o que traz sentimento de realização, mesmo em face de todas as dificuldades encontradas em seu dia a dia. Nessa perspectiva, a presença de um psicólogo escolar atuando junto a alunos e professores poderia alavancar ainda mais a relação professor-aluno e otimizar a aprendizagem, o que poderia eventualmente desencadear ainda mais realização profissional do professor. (23)

Uma enquete realizada pela Nova Escola ${ }^{1}$ mostra que apenas $49 \%$ dos docentes sentem-se realizados profissionalmente. Muitos se sentem desvalorizados pelo governo, pela rede de ensino, pela direção da escola, pelos alunos, pelos familiares e pela sociedade como um todo. É preciso conceder mais valorização ao professor no Brasil, a fim de que o número de professores realizados profissionalmente, como os participantes desta pesquisa, cresça em quantidade e que a opção de ser professor fortaleça nas escolhas profissionais.

\subsection{Experiências relacionadas ao esgotamento profissional}

\subsubsection{Sintomas físicos}

Os sintomas físicos do esgotamento profissional são manifestações de desordem fisiológica que levam ao adoecimento do indivíduo. Nesse caso, podemos notar através das entrevistas que as professoras Maria, Manoela e Márcia apresentam queixas desses sintomas, destacando-se dores na coluna, hérnia de disco, dores de cabeça (que também pode ter origem emocional) e incômodo no braço:

\footnotetext{
${ }_{1}$ Disponível em: http://ow.ly/EdJQ3056L97. Acesso em: 12/10/16.
}

Rev. Psicol Saúde e Debate. Jan., 2017:2(2):76-95. 
[...] tenho um pouquinho às vezes de dor nas costas, de posição de quadro, de posição de ficar sentada horas seguidas corrigindo... [...] Estou em tratamento devido a hérnias de disco, por ficar muito tempo numa mesma posição.

(Maria)

[...] às vezes algum problema de braço [...].

(Manoela)

[...] ano passado internei seis vezes, com enxaqueca durante 24 horas [...].

(Márcia)

O professor Marcos não apresenta nenhuma queixa sobre sintomas físicos; apenas relatou sentir-se cansado no final do dia de trabalho:

[...] tenho diabetes mais é hereditário, minha mãe teve e eu nunca com 22 anos como professor nunca tirei uma licença de saúde [...]

[...]

Olha, no final do dia me sinto um pouco cansado [...].

(Marcos)

Por fim, a professora Mercedes não revelou nenhuma queixa relacionada a sintoma físico de esgotamento profissional.

Ou seja, sintomas físicos de esgotamento profissional estão presentes nos relatos de três professores. Esses relatos corroboram sintomas descritos em outros estudos. Um deles observou em 58 escolas de Salvador, com professores de ambos os sexos, que as principais queixas relacionadas à saúde entre os professores são dor de garganta, dor nas pernas, dor nas costas, rouquidão e cansaço mental(24).

\subsubsection{Sintomas psíquicos}

No tocante a sintomas psíquicos, as professoras Maria, Márcia e Manoela revelaram já ter apresentado algum desses sintomas, como mostram as falas a seguir:

Rev. Psicol Saúde e Debate. Jan., 2017:2(2):76-95. 
[...] tive uma queda aqui na escola em 2014, no final do ano, em outubro e eu bati a garganta, em um bebedouro, [...] ai eu fiquei mais ou menos um mês tipo afônica, as vezes eu ainda sinto um pouquinho quando eu falo mais alto, mas o médico falou que não ficou sequela nem nada, eu acho que é mais psicológico, na época eu assustei demais e achei que eu tinha quebrado isso aqui e não ia falar mais; na hora eu não falava, então eu acho que isso ficou um trauma [...]. (Maria)

[...] ano passado internei seis vezes, com enxaqueca durante 24 horas, ai eu consultei, internei com dois neurologistas acreditando que a minha enxaqueca era caso para neurologista; posteriormente procurei um psiquiatra e o diagnóstico foi ansiedade e um pouco de depressão, então o cansaço, o excesso de trabalho, porque eu trabalhava mais de 55 horas por semana, me levou ao estresse, à ansiedade e hoje já tem um ano e um mês que eu continuo tomando remédio para ansiedade e pra dormir.

(Márcia)

[Me sinto] cansada né, eu não seria mentirosa, pra não dizer que estou cansada, porque além da questão de estar com esse aluno né, [...] atualmente eu também estou com o ensino além do médio, com o ensino fundamental, o ensino fundamental é muito desgastante, são meninos muito inquietos, então quando chega o final de semana eu estou realmente muito cansada [...] é a questão mesmo do cansaço, do grande tempo de trabalho, então a gente já está realmente mais desgastada...

(Manoela)

O professor Marcos não relatou sintomas psíquicos em sua fala. Pelo contrário, revelou não se cansar mentalmente de ser professor:

Rev. Psicol Saúde e Debate. Jan., 2017:2(2):76-95. 
[...] mentalmente eu não me canso de ser professor [...].

(Marcos)

Vale ressaltar que o cansaço relatado pelos docentes pode ser atribuído tanto ao físico quanto ao mental, considerando-se sua rotina de trabalho. Mercedes e Manoela não manifestaram nenhum sintoma psíquico de esgotamento profissional.

\subsubsection{Sintomas comportamentais}

Os sintomas comportamentais ocorrem por uma desordem psicológica, mas que afetam as ações do indivíduo, ou seja, seus comportamentos. Nas entrevistas, somente o professor Marcos relatou irritabilidade com a questão burocrática da escola. No caso dos outros professores, não houve relatos que evidenciassem sintomas comportamentais de esgotamento profissional.

\subsubsection{Sintomas defensivos}

Os sintomas defensivos estão ligados a maneiras que o indivíduo utiliza de fuga ou esquiva em determinadas situações que são angustiantes e que interferem na realização de atividades do seu dia a dia ${ }^{(10)}$. Os sintomas defensivos consistem na defesa do Eu, onde segundo a psicanálise, são mecanismos inconscientes de resolução de conflitos, como exemplo as fantasias, as projeções, as sublimações, o recalcamento, e as regressões ${ }^{(25)}$.

Nesta pesquisa, Maria relata dormir durante sua trajetória para o trabalho, como forma de esquivar-se do medo do perigo que enfrentava na estrada:

[...] viajei praticamente quinze anos; daqui a XXX são aproximadamente $130 \mathrm{~km}$ e o perigo de estrada... Graças a Deus eu nunca tive nenhum acidente, nem nada que eu estivesse inclusive aconteceu no dia em que eu não tinha aula, mas é muito perigoso, eu ficava muito tensa sabe, eu até aprendi a com o passar do tempo a dormir, ia dormindo aqui e chegava dormindo lá, se acontecesse alguma coisa no caminho eu estaria dormindo [...]

(Maria)

Não houve outro relato de sintomas defensivos durante as entrevistas. No geral, os dados revelam que os professores enfrentam as situações da maneira que conseguem, não fugindo de suas obrigações. Apenas Márcia relatou ter sido afastada por motivo de doença 
ocasionada também pelo ambiente de trabalho; todavia, não conseguiu se manter afastada, alegando que o afastamento contribuiria para o agravamento da doença.

\section{CONSIDERAÇÕES FINAIS}

Este estudo buscou mapear experiências profissionais de professores da educação básica pública visando compreender sua qualidade de vida no trabalho, observando a eventual inter-relação dessas experiências com indícios de esgotamento profissional. Os resultados mostraram que os professores enfrentam uma rotina pesada de trabalho, o que desencadeia cansaço, alimentação em horários irregulares, trabalho após o expediente, falta de momentos de lazer e sintomas como dores de cabeça e no corpo. Isso afeta negativamente sua qualidade de vida, mas, apesar disso, relatam se sentir realizados na profissão e buscam maneiras de contornar tais adversidades. Apenas uma professora relatou adoecimento ao longo de seus anos de trabalho, precisando se afastar temporariamente. Os demais não se queixam de adoecimento, o que não comprovou nossa hipótese de pesquisa. Em síntese, as experiências de trabalho dos participantes deste estudo indicam prejuízos em sua qualidade de vida, mas não indicaram indícios significativos de esgotamento profissional.

Recomenda-se a realização de estudos com amostras populacionais mais abrangentes, os quais focalizem experiências de trabalho de professores novatos e experientes, investigando-se como cada grupo (novatos e experientes) experiência sua profissão e se professores mais experientes, como os deste estudo, apresentam menos propensão ao esgotamento profissional em relação aos professores novatos. Caso isso se comprove, há de se investigar o motivo disso ocorrer.

\section{REFERÊNCIAS}

1. Monteiro R, Braile DM, Brandau R, Jatene FB. Focus on quality of life. Rev Bras Cir Cardiovasc orgao Of da Soc Bras Cir Cardiovasc [Internet]. 2010;25(4):568-74. Available from: http://www.ncbi.nlm.nih.gov/pubmed/21346353

2. Ferreira MC, Mário C:, Ferreira C. Ergonomia da Atividade aplicada à Qualidade de Vida no Trabalho: lugar, importância e contribuição da Análise Ergonômica do Trabalho (AET). 
São Paulo [Internet]. 2015;40(131):303-7657. Available from: http://dx.doi.org/10.1590/03037657000074413

3. Oliveira RR de, Silva IB, Castro DSP, Limongi-França AC. Qualidade De Vida No Trabalho (Qvt): Um Estudo Com Professores Dos Institutos Federais. Holos [Internet]. 2015;6:432. Available from: http://www2.ifrn.edu.br/ojs/index.php/HOLOS/article/view/1726

4. Pereira ÉF, Teixeira CS, Andrade RD, Bleyer FTDS, Lopes ADS. Associação entre o perfil de ambiente e condições de trabalho com a percepção de saúde e qualidade de vida em professores de educação básica. Cad Saúde Coletiva [Internet]. 2014;22(2):113-9. Available from: http://www.scielo.br/scielo.php?script=sci_arttext\&pid=S1414$462 X 2014000200113 \& \operatorname{lng}=$ pt\&nrm=iso\&tlng=en

5. DIAS D de S, BARROS ME, SILVA OIV, CAMPOS GM. Das dores e delícias do trabalho docente: uma anpalise do trabalho. Trab e Educ. 2013;22(2):169-81.

6. Estado AMTO, Benevides-pereira AMT. O e a b b. 2002;(I):4-11.

7. Mary Sandra Carlotto, Gobbi MD. Sindrome de Burnout: um problema do individuo ou do seu contexto de trabalho? Aletheia. 1999;10:103-14.

8. Carlotto MS, Câmara SG. Preditores da Síndrome de Burnout em professores. Psicol Esc e Educ. 2007;11(1):101-10.

9. Brasil MDS, Almeida I, Tavanti A, Ghelardi E. Doenças relacionadas ao trabalho [Internet]. Vol. 67, Série A Normas e Manuais Técnicos. 2001. 580 p. Available from: http://scholar.google.com/scholar?hl=en\&btnG=Search\&q=intitle:Doen?as+relacionadas+ao +trabalho\#8

10. BENEVIDES-PEREIRA AMT. Burnout: quando o trabalho ameaça o bem estar do trabalhador. 3rd ed. São Paulo: Casa do Psicólogo; 2008. 
11. CODO W. Educação: Carinho e Trabalho: Burnout, a síndrome da desistência do educador, que pode levar à falência da educação. 4th ed. Petrópolis: Vozes; 1999.

12. Brasil. Confederação Nacional dos Trabalhadores em Educação. Brasília; 2008.

13. Carlotto MS, Palazzo LDS. Síndrome de burnout e fatores associados: um estudo epidemiológico com professores. Cad Saude Publica. 2006;22(5):1017-26.

14. Gasparini SM, Barreto SM, Assunção AA. O professor, as condições de trabalho e os efeitos sobre sua saúde. Educ e Pesqui. 2005;31(2):189-99.

15. CODO W. Por Uma Psicologia Do Trabalho. São Paulo: Casa do Psicólogo; 2006. 294 p.

16. Benevides-Pereira AMT. Considerações sobre a síndrome de burnout e seu impacto no ensino TT - The burnout syndrome and its impact on teaching. Bol psicol [Internet]. 2012;62(137):155-68. Available from: http://pepsic.bvsalud.org/scielo.php?script=sci_arttext\&pid=S0006-59432012000200005

17. Teixeira FG, Silva MRS da, Medeiros GL. Síndrome de Burnout - a interface entre o trabalho na àrea da educação e na enfermagem. Rev Enferm Ref. 2010;III Série(nº 2):101-9.

18. Gil AC. Como Elaborar Projetos de Pesquisa. Como Elaborar Projetos de Pesquisa. 2002. 1-176 p.

19. Dartel Ferrari de Lima, Levy RB, Luiz O do C. Recomendações para atividade física e saúde: consensos, controvérsias e ambiguidades. Rev Panam Salud Publica. 2014;36(3):164-70.

20. Araújo T, Sena I, Viana M, Araújo E. Mal - Estar Docente: Avaliação de condições de trabalho e saúde em uma instituição de ensino superior. Rev Baiana Saúde Pública. $2005 ; 29(1): 6-21$.

Rev. Psicol Saúde e Debate. Jan., 2017:2(2):76-95. 
21. Reis EJFB dos, Araújo TM de, Carvalho FM, Barbalho L, Silva MO e. Docência e Exautão Emocional. Educ Soc. 2006;27(94):251-75.

22. Morin E, Tonelli MJ, Pliopas ALV. O trabalho e seus sentidos. Psicol Soc. 2007;19(spe):47-56.

23. Moreira IG, Oliveira RF dos S. A importância do trabalho do psicólogo no ambiente escolar: perspectivas da educação na atualidade. Psicol e Saúde em Debate [Internet]. 2016;2(EE):14-27. Disponível em: https://psicodebate.wordpress.com/edicoesanteriores/volume-2-edicao-especial-2016/a-importancia-do-trabalho-do-psicologo-noambiente-escolar-perspectivas-da-educacao-na-atualidade/

24. Silvany-Neto AM, Araújo TM de, Dutra FRD, Azi GR, Alves RL, Kavalkievicz C, et al. Condições de trabalho e saúde de professores da rede particular de ensino de salvador, Bahia. Vol. 24, Rev. Baiana de Saúde Públ. 2000. p. 42-56.

25. Mesquita R, Duarte F. Dicionário de Psicologia. Lisboa: Plátano; 1996. 217 p. 